\title{
Teaching Note Empowering Online Undergraduate Social Work Students to Address Their Stress
}

KATHERINE M. MCCARTHY

Effective self-regulation is a critical aspect of social work. Unmanaged stress can impair a social worker's effectiveness. BSW students must demonstrate the capacity for cognitive and affective self-regulation to graduate, yet they may be expected to develop these skills outside of their academic program. This article describes a pedagogical strategy for encouraging proactive stress management practices in BSW students during online theory and practice courses at a Midwest public university. Students completed weekly self-care quizzes, which required them to rate their stress, create a plan to reduce this stress, and assess their efforts. Students felt this activity helped them to reflect and take action while also strengthening their relationships with their online instructor. Although this effort was employed in the years prior to COVID-19, the relevance of encouraging active stress management in the time of the pandemic and widespread virtual learning has only increased.

KEYWORDS BSW education, stress management, self-care, emotional regulation, online education

The Council on Social Work Education (CSWE, 2015) Educational Policy and Accreditation Standards (EPAS) require social work students not only to accumulate knowledge, skills, and values, but also to demonstrate a capacity for affective regulation that will support their professional efforts. Researchers emphasize the need to help social work students become aware of their own emotions and effectively manage them (Baird, 2016; Iacono, 2017; Ikebuchi \& Rasmussen, 2014). Self-care is increasingly identified as a necessary aspect of healthy social work practice and a way to reduce academic stress (Lee \& Miller, 2013; O’Neill et al., 2019; Willis \& Molina, 2019). Teaching effective self-care practices can be a method of helping students develop the needed affective regulation. This teaching note demonstrates that weekly self-care quizzes in online social work undergraduate courses are a simple and direct way to encourage student wellness during the semester, which can instill stress management skills for professional practice.

The Journal of Baccalaureate Social Work, Vol. 25 (2020)

(c) 2020, The Association of Baccalaureate Social Work Program Directors. All rights reserved

This is the author's manuscript of the article published in final edited form as:

McCarthy, K. M. (2020). Empowering Online Undergraduate Social Work Students to Address Their Stress. Journal of Baccalaureate Social Work, 25(1), 231-243. https://doi.org/10.18084/1084-7219.25.1.231 


\section{Classroom Efforts to Foster Student Self-Regulation}

The 2015 EPAS states that BSW students must demonstrate ethical and professional behavior (Competency 1) to graduate (CSWE, 2015). Specifically, students must "use reflection and self-regulation to manage personal values and maintain professionalism in practice situations" (p. 7). This includes managing one's emotions such that they do not hinder or interfere with one's social work practice. Undergraduate social workers are often young adults who may be in the midst of developing their affective regulation skills (Reisser, 1995). These skills could include recognizing their emotions and the triggers to these emotions, as well as choosing how to express them. BSW students begin work toward their degrees with varying expertise in self-regulation and affect management. To meet our obligations as educators, it is our job to help all admitted BSW students develop the capacity for appropriate self-regulation rather than to expect them to rely on previous training.

In a qualitative study of BSW educators describing the "use of self" in social work and the value of nurturing this capacity in their students, Liechty (2018) contends that students' personal selves have to be a central aspect of their education, including the capacity for self-reflection and emotional maturity. If self-management is not discussed in class, then it is possible the only times a student's emotional development is addressed is in conversations with supervisors and advisors or during student performance reviews. These intervention efforts may occur too late to help struggling BSW students. Preventive measures, however, such as enhancing self-regulation with class assignments, could help all students effectively meet the first EPAS competency (CSWE, 2015). Although BSW instructors are not students' therapists, educators have articulated the need for social work students to be trained in selfregulating techniques because of the emotional demands of the work (Ikebuchi $\&$ Rasmussen, 2014).

Not only have educators recognized that attention to student wellness beyond the classroom is fundamental to fostering effective social workers (Fouché \& Martindale, 2011), but they have also explored different pedagogical methods of encouraging wellness. Social work educators in different parts of the world have tried to train undergraduate social work students in mindfulness. A few examples include 2 hours of mindfulness training a week for 6 weeks in Belfast (Roulston et al., 2018), an 8-week course to increase self-awareness to manage stressors for undergraduate students in Israel (Birnbaum 2008), and 100 minutes total of mindfulness training in a semester-long BSW practice class 
in the United States (Thomas, 2017). Social work students also benefit from stress management groups, which have included those provided by licensed social workers (Clements \& Minnick, 2012) and relaxation trainings, such as a 1.5 hour weekly program for undergraduate social work students in Japan (Hirokawa et al., 2002). Although there is promise in different methods of teaching mindfulness and stress management, these methods can be time consuming or challenging to provide at a distance.

Distance education is an increasingly common method for students to pursue a BSW degree. Even prior to the near universal online modality used during the spring 2020 COVID-19 pandemic, approximately $47.7 \%$ of accredited BSW programs offered an online component (CSWE, 2020). Amid social work educator concerns that online teaching methods lead to more transactional expectations and less transformational learning (Reyes \& Segal, 2019), it is necessary to develop pedagogical strategies that will prepare BSW students for managing the affective demands of practice. This includes their readiness to manage their stress before it negatively affects clients. This teaching note presents the use of weekly self-care quizzes as a way to foster the stress management skills of online BSW students. This can contribute to the growing pedagogy expanding methods of effectively fostering emotional regulation skills with online university students (Stallman et al., 2019).

\section{Method}

I developed the weekly self-care quizzes and incorporated them into two sequential junior-level online social work courses (Course 1 and Course 2) on general practice and theory in the 2016-2017 and 2017-2018 years. Course 1 occurred in the fall semester and Course 2 in the spring semester. This study earned exempt status from the university institutional review board. A description of the assignment along with demographics and overview of student results are discussed below. This includes a retrospective content and thematic analysis of students' perspectives on their own stress management efforts and the students' perspectives on the overall assignment.

Fifty-six students participated in the surveys, with 35 students participating in both courses and 21 participating in either Course 1 or Course 2. Approximately $57 \%$ of the students were White females; $30 \%$ were Black females; $9 \%$ were Latina females; and $4 \%$ were White males. In addition, about one third of the students were parents, and a majority of the students worked in 
Figure 1 Weekly self-care quiz questions

1. 1-10 stress scale: Where do you rank yourself right now?

2. How did your plan from last week work out? If you did it, how did it help? If you didn't do it, what got in your way?

3. What is a concrete step you can take over the next week to lower that number? Be realistic.

addition to attending school. Although all students had access to the self-care quizzes, a handful of students did not participate consistently. These assessments were monitored and responded to weekly by the instructor and analyzed after the courses were completed.

\section{Self-Care Quiz Description}

Students were expected to complete the self-care quizzes weekly in the online practice skills courses, which contributed to a small part of the students' participation grade. Each week these quizzes provided brief information on an aspect of self-care and wellness or an inspirational quote or picture. Reliable websites and texts were used and cited, including sources such as the Mayo Clinic and The A-to-Z Self-Care Handbook for Social Workers and Other Helping Professionals (Grise-Owens et al., 2016). Information about college counseling services was posted as a reference in the quiz.

The self-care quizzes helped students increase their cognitive awareness of their relationship with stress and the steps they could choose to address it. During the first week of Course 1, students were invited to identify common methods of physical, emotional, and psychological self-care. During the second week, students were introduced to a stress scale (1-10, with 10 being extremely high stress). Students were asked to describe physical, mental, emotional, or social warning signs indicating they were at a 3 , a 6 , or a 9 , respectively, as a way to help them differentiate their response to stress. Beginning in the third week, students were asked to score their current stress levels and identify plans to reduce that number over the upcoming week. An evaluative component was added in the fourth week, when students were asked to reflect on their previous plan. This new component of assessment and reflection was included in each subsequent week, noted in Figure 1. The quizzes took approximately 2 minutes to complete. Course 2 continued these weekly assessments, reflections, and goal 
setting during the spring semester with different emphases. Students reflected on this assignment in its entirety at the end of each course.

Only the student and the instructor could view each response, and the instructor could respond privately. Typically, the comment was brief, consisting of either a simple acknowledgement or an effort to encourage the student. If a student shared a particularly difficult or painful situation, the instructor would respond more specifically, expressing empathy in a sentence or two. On rare occasions (usually if a student was expressing depressive symptoms or divulged a friend or family member's death), the instructor would e-mail to follow up, either to schedule a phone call, encourage contact with the college counseling center, or communicate about altering an assignment deadline.

\section{Self-Care Quiz Results}

The self-care quizzes prompted student reflection on their self-care methods, stress indicators, weekly stress levels, weekly goals, and weekly progress. Their categorized responses are presented in this section. Although not generalizable to all BSW juniors, they provide insight into common stressors, warning signs, and stress management efforts. Student reflections on the assignment are also discussed.

All 45 students in Course 1 described how they anticipated incorporating self-care into their lives. They responded to open-ended questions about what they do to take care of their physical, social, and psychological wellness. This served to increase their awareness of their strategies and that these methods could be used throughout the semester. More than $50 \%$ of the respondents described specific methods to strengthen physical health, such as exercising, healthy eating, and sufficient rest. The most identified methods of caring for psychological wellness included taking time for self, choosing one's mindset, focusing on physical wellness, venting to family of friends, and listening to music. To manage social wellness, students most identified the need to spend time with other people, vent to family or friends about stress, or choose a positive mindset.

Students also described their personal stress levels and warning signs. Personal signs of distress centered on cognitive functioning, physical functioning, interactivity, emotions, and productivity, as is evident in Table 1. Students described cognitive changes at different stress levels; at lower stress levels, they noticed themselves constantly thinking about tasks; and at higher stress levels, they struggled to think at all. Students also reported increasing symptoms of physical distress as their stress levels increased. Students identified 
Table 1 Personal Signs of Stress on 1-10 Stress Scale ( $N=45)$

\begin{tabular}{|c|c|c|c|c|}
\hline & & $\begin{array}{l}\text { Signs } \\
\text { at } 3\end{array}$ & $\begin{array}{l}\text { Signs } \\
\text { at } 6\end{array}$ & $\begin{array}{l}\text { Signs } \\
\text { at } 9\end{array}$ \\
\hline \multirow{3}{*}{$\begin{array}{l}\text { Cognitive } \\
\text { functioning }\end{array}$} & Constantly thinking about what to do next & 11 & 10 & 0 \\
\hline & Start having trouble focusing & 5 & 3 & 2 \\
\hline & Trouble thinking & 5 & 0 & 12 \\
\hline \multirow{3}{*}{$\begin{array}{l}\text { Physical } \\
\text { functioning }\end{array}$} & Some physical distress & 10 & 18 & 19 \\
\hline & Staying up late or cannot sleep & 5 & 7 & 6 \\
\hline & Feeling fatigued & 6 & 5 & 11 \\
\hline \multirow[t]{2}{*}{ Interactivity } & Withdrawing & 7 & 16 & 26 \\
\hline & Shutting down & 1 & 0 & 11 \\
\hline \multirow[t]{2}{*}{ Emotions } & Beginning to feel irritability and anxiety & 5 & 4 & 0 \\
\hline & Highly emotional & 5 & 12 & 28 \\
\hline \multirow[t]{3}{*}{ Productivity } & Taking steps toward productivity & 4 & 7 & 5 \\
\hline & Denying of avoiding tasks & 3 & 7 & 2 \\
\hline & Neglecting necessary tasks & 1 & 6 & 6 \\
\hline
\end{tabular}

the beginnings of irritable emotions at lower stress levels and described becoming highly emotional at a stress level of 9. Student descriptions of productivity or task avoidance seemed to vary. The mean stress levels were charted and, unsurprisingly, stress reduction seemed to coincide with October break, Thanksgiving break, December break, and Spring break.

Each week students were asked to identify which steps they would take to reduce their stress level. This offered an experiential opportunity to help them move from "feeling stressed" to choosing a behavior or action to address the stress. Commonly identified stress management goal themes included completing school work in advance or on time, creating a schedule to complete schoolwork, and choosing their mindset, which meant deciding to focus on the positive, do one task at a time, or maintain confidence that they would succeed. Students also made goals of maintaining their current stress reduction plan and addressing specific issues that required immediate attention and resolution, such as childcare, car repairs, house maintenance, or confusion in a class.

In evaluating their stress management efforts students often directly stated whether the plan worked. Although they were not asked about the reasons for their stress, students also readily shared them. Sometimes they described barriers to the stress management plan. The barriers they identified as interfering with their goals were most frequently their personal lives, academic or work 
Figure 2 Student comments about self-care quizzes at end of each semester $(N=77)$



demands, and forgetting the goal. Often they shared successes that week related to the plan as well as happy events in their lives.

At the end of the spring course, Course 2, students were asked whether the self-care quizzes had altered their feelings, thoughts, or behaviors. Although a handful wrote that the quizzes were unnecessary or ineffective, $91.9 \%$ of respondents indicated that the self-care quizzes had helped them initiate a new plan or an action. Students also described becoming more aware of their own stress reactions and options for stress management. As one student observed, "they definitely $100 \%$ altered my thoughts, feelings, and behaviors. I am actually going to make every effort to continue to do this kind of self-care evaluation and document it once a week because it was so beneficial." Students also stated that the quizzes helped them feel better.

These self-care evaluations altered how I think about stress and what I do to reduce stress. I usually just think, "Wow, I am really stressed out," and then I do not really do anything about it. These evaluations made me assess the stress and change my behavior to reduce the stress.

At the end of each course students elaborated on their thoughts about participating in the self-care quizzes. See Figure 2 for an overview of student reactions. Most responses indicated that the quizzes offered them perspective, made them think about stress differently, and coached them to address the stress. Students stated that they enjoyed the quizzes. Some of these students 
reported feeling that the instructor cared about them specifically or they liked having a chance to vent their frustrations. Students also indicated that they were thankful for the quizzes and said that the quizzes taught them to take time for themselves. A few responses indicated dissatisfaction with the repetitive nature of the questions or denied the quizzes had value.

\section{Discussion}

These self-care quizzes can be a way to foster BSW student capacity for selfreflection and self-regulation, which support the EPAS competency around ethical and professional behavior and are aspects of emotional intelligence that social workers need (Ingram, 2013). Through repetition of goal setting supported by instructor attention, the students practiced self-assessing and prioritizing their stress management. When Grise-Owens and colleagues (2018) incorporated regular self-care plans, weekly written updates, and faculty feedback accountability groups for their MSW students in on-the-ground classes, their students indicated they were more likely to continue to incorporate self-care into their future practice. Students taking these self-care quizzes also articulated an expectation to continue to use this skill in the future and described encouraging family members to do this. The self-care quizzes helped students to better manage their life and responsibilities and set goals, which could also reinforce this as a life skill. Although the students often focused on completing assignments in advance and becoming more organized, they also identified addressing additional stressful parts of their life, such as talking to a professor, getting a new job, or setting limits with friends and colleagues. Taking proactive measures to assist one's self can serve BSW students well in their senior year-long practicum and future careers.

Beyond increasing cognitive and affective focus on personal stress management, the self-care quizzes appeared to facilitate positive student-instructor relationships. Students noted feeling that the instructor cared about them and what they were going through in their lives. The relationship between the instructor and the student is a core aspect of the learning process, especially in social work, where instructor efforts to attune to students emotionally helps them to do this with others (Farber \& Penney, 2020). Students are more effective in class when they feel connected to their instructors (Okech et al., 2014) and when they believe their instructors like them (Wilson, 2008). Online students are more satisfied with their courses when they perceive high levels of instructor involvement (Ladyshewsky, 2013). In a study of 193 students' perceptions of their online instructors' misbehaviors, Vallade and 
Kaufman (2018) emphasize the need for instructors to be attentive, because students can make negative assumptions about instructors based on limited information available through online communication. Nurturing this relationship online requires different intention and effort than in on-the-ground classes but is vitally important.

Originally described and explored by Garrison and colleagues (2000), the Community of Inquiry framework highlights the interactive aspects of teaching presence, cognitive presence, and social presence in fostering deep learning in online courses (see Garrison \& Akyol, 2013 for more information). Researchers have expanded on these concepts to include instructor social presence (Pollard et al., 2014; Richardson \& Lowenthal 2017). Online students experience instructor social presence when they feel they know their instructors and that their instructors are involved (Richardson \& Lowenthal, 2017). Instructor social presence is established through communication efforts, evidence of the instructor's persona, and how the course is designed (Richardson \& Lowenthal, 2017). The self-care quizzes incorporated all these aspects of instructor social presence by embedding direct communication between the student and instructor throughout the course, allowing students to feel known and cared for by the instructor. These interactions can counter the limitations in connection sometimes experienced in online social work education (Haley, 2010). Instructor satisfaction in teaching is related to connection to students (Bolliger et al., 2014; DiClemente et al., 2013; Wininger \& Birkholz, 2013), so the selfcare quizzes could strengthen instructor commitment as well.

Although these quizzes may not be appropriate for students who are already highly organized and proactive, like the few dissatisfied students or who may have felt so overwhelmed that they elected not to complete them, the majority of the BSW students really valued them. This highlights the possibility that these quizzes might need to be omitted or adjusted for some students who are effectively managing stress.

\section{Additional Considerations}

A few considerations should be kept in mind when implementing this activity in online BSW classrooms. It is recommended that instructors using such a regular check to enable this sort of student growth and support be organized, empathic, curious, and actively affirming. Instructors using these sorts of regular self-care quizzes must commit to reading through them on a regular basis and will get the most out of the activity if they enjoy learning more about their students. Instructors might feel that this assignment demands a different set of 
boundaries between themselves and the students; however, they are not offering more than the general support that has long been provided in on-the-ground classrooms. Although these students never communicated extremely urgent issues, this potential outcome could require the instructor to take immediate action, as they would in an on-the-ground course. Although this sample was predominantly female, other information about student demographics was limited, making it difficult to identify characteristics differentiating students who did participate in the quizzes from students who did not. The quizzes might be received differently by students with diverse backgrounds and needs. Future research might clarify which student needs are best addressed with this sort of weekly self-quiz and might explore differences between online and onthe-ground effectiveness and methodology for fostering stress management skills.

\section{Conclusion}

Students navigate personal maturation, academic stressors, family demands, work obligations, and trauma histories while aspiring to develop into effective social workers. Social work educators must foster emotional regulation skills in a way that will help students manage professional obligations with clients and communities while having personally satisfying lives. Building in self-care quizzes as a part of these online courses is a valuable way to foster student selfawareness, proactive stress management, and instructor-student connection in online educational communities.

\section{References}

Baird, S. L. (2016). Conceptualizing anxiety among social work students: Implications for social work education. Social Work Education, 35, 719-732. https://doi.org/10.1080/02615479.2016.1184639

Birnbaum, L. (2008). The use of mindfulness training to create an "accompanying place" for social work students. Social Work Education, 27, 837-852. https://doi.org/10.1080/02615470701538330

Bolliger, D. U., Inan, F. A., \& Wasilik, O. (2014). Development and validation of the Online Instructor Satisfaction Measure (OISM). Educational Technology \& Society, 17(2), 183-195.

Clements, J. A., \& Minnick, D. J., (2012) But I'm too stressed to learn about groups!: Using stress-management groups to teach group work skills. Social Work with Groups, 35(4), 330-344. https://doi.org/10.1080/01609513.2012.664323 
Council on Social Work Education (2015). 2015 Educational policy and accreditation standards. Author.

Council on Social Work Education (CSWE). (2020). Annual statistics on social work education in the United States. Retrieved from https://cswe.org/getattachment/Research-Statistics/2019-Annual-Statisticson-Social-Work-Education-in-the-United-States-Final-(1).pdf.aspx

DiClemente, R., Ditrinco, E., Gibbons, K., \& Myers, S. (2013). The relationship between instructor job satisfaction and communicator style and socio-communicative orientation. Communication Research Reports, 30(4), 347-351. https://doi.org/10.1080/08824096.2013.836481

Farber, N., \& Penney, P. (2020). Essential and neglected: Transforming classroom learning through relationship. Journal of Teaching in Social Work, 40(2), 95-113. https://doi.org/10.1080/08841233.2020.1726553

Fouché, C., \& Martindale, K. (2011). Work-life balance: Practitioner well-being in the social work education curriculum. Social Work Education, 30, 675-685. https://doi.org/10.1080/02615479.2011.586566

Garrison, D. R., \& Akyol, Z. (2013). The community of inquiry theoretical framework. In Moore, M. G. (Ed.). Handbook of distance education. Routledge.

Garrison, D. R., Anderson, T., \& Archer, W. (2000). Critical inquiry in a textbased environment: Computer conferencing in higher education. The Internet and Higher Education, 2(2-3), 87_105.

Grise-Owens, E., Miller, J., \& Eaves, M. (2016). The A-to-Z Self-Care Handbook for Social Workers and other Helping Professionals. New Social Worker Press.

Grise-Owens, E., Miller, J. Escobar-Ratliff, L., \& George, N. (2018). Teaching note-Teaching self-care and wellness as a professional practice skill: A curricular case example. Journal of Social Work Education, 54, 180-186. https://doi.org/10.1080/10437797.2017.1308778

Haley[A1][A2], K. N. (2010). Wired and tired: The cool and the agony of teaching online. Revista de Asisten__Social_9(1), 58-63.

Hirokawa, K., Yagi, A., \& Miyata, Y. (2002). An examination of the effects of stress management training for Japanese college students of social work. International Journal of Stress Management, 9(2), 113-123. https://doi.org/10.1023/A:1014906820573

Iacono, G. (2017). A call for self-compassion in social work education. Journal of Teaching in Social Work, 37, 454-476. https://doi.org/10.1080/08841233.2017.1377145 
Ikebuchi, J., \& Rasmussen, B. M. (2014). The use of emotions in social work education. Journal of Teaching in Social Work, 34(3), 285-301. https://doi.org/10.1080/08841233.2014.909378

Ingram, R. (2013). Locating emotional intelligence at the heart of social work practice. British Journal of Social Work, 43, 987-1004. https://doi.org/10.1093/bjsw/bcs029

Ladyshewsky, R. K. (2013). Instructor presence in online courses and student satisfaction. International Journal for the Scholarship of Teaching \& Learning, 7(1), 1-23. https://doi.org/10.20429/ijsotl.2013.070113

Lee, J., \& Miller, S. E. (2013). A self-care framework for social workers. Families in Society: The Journal of Contemporary Social Services, 94(2), 96-103.

Liechty, J. (2018). Exploring use of self: Moving beyond definitional challenges. Journal of Social Work Education, 54, 148-162. https://doi.org/10.1080/10437797.2017.1314836

Okech, D., Barner, J., Segoshi, M., \& Carney, M. (2014). MSW student experiences in online vs. face-to-face teaching formats. Social Work Education, 33, 121-134. http://doi.org/10.1080/02615479.2012.738661

O’Neill, M., Yoder Slater, G., \& Batt, D. (2019) Social work student self-care and academic stress, Journal of Social Work Education, 55, 141-152, https://doi.org/10.1080/10437797.2018.1491359

Pollard, H., Minor, M., \& Swanson, A. (2014). Instructor social presence within the Community of Inquiry framework and its impact on classroom community and the learning environment. Online Journal of Distance Learning Administration, 17(2), 41-52.

Reisser, L. 1. (1995). Revisiting the seven vectors. Journal of College Student Development, 36, 505-511.

Reyes, M., \& Segal, E. A. (2019). Globalization or colonization in online education: Opportunity or oppression? Journal of Teaching in Social Work, 39(4/5), 374-386. https://doi.org//10.1080/08841233.2019.1637991

Richardson, J. C., \& Lowenthal, P. (2017). Instructor social presence: A neglected component of the Community of Inquiry. ELearning \& Software for Education, 2, 531-536. https://doi.org/10.12753/2066-026X-17-160

Roulston, A., Montgomery, L., Campbell, A., \& Davidson, G. (2018). Exploring the impact of mindfulness on mental wellbeing, stress, and resilience of undergraduate social work students. Social Work Education, 37, 157-172. https://doi.org/10.1080/02615479.2017.1388776

Stallman, H. M., Ohan, J. L., \& Chiera, B. (2019). Reducing distress in university students: A randomised control trial of two online 
interventions. Australian Psychologist, 54(2), 125-131.

https://doi.org/10.1111/ap.12375

Thomas, J. T. (2017). Brief mindfulness training in the social work practice classroom. Social Work Education, 36(1), 102-118.

https://doi.org/10.1080/02615479.2016.1250878

Vallade, J. I., \& Kaufmann, R. (2018). Investigating instructor misbehaviors in the online classroom. Communication Education, 67, 363-381.

https://doi.org/10.1080/03634523.2018.1467027

Wilson, J. H. (2008). Instructor attitudes toward students: Job satisfaction and student outcomes. College Teaching, 56(4), 225-229.

Willis, N. G., \& Molina, V. (2019). Self-care and the social worker: Taking our place in the code. Social Work, 64(1), 83-86.

https://doi.org/10.1093/sw/swy049

Wininger, S., \& Birkholz, P. (2013). Sources of instructional feedback, job satisfaction, and basic psychological needs. Innovative Higher Education, 38(2), 159-170. https://doi.org/10.1007/s10755-012-9229-9

Katherine M. McCarthy is an assistant professor at Indiana University. 